\title{
Special issue in honor of Abraham Neyman
}

\author{
Olivier Gossner ${ }^{1}$ • Ori Haimanko ${ }^{2}$ - Eilon Solan ${ }^{3}$
}

Published online: 16 March 2016

(C) Springer-Verlag Berlin Heidelberg 2016

\section{Preface}

The International Journal of Game Theory is proud to publish a special issue in honor of the contributions of Prof. Abraham Neyman to Game Theory. Abraham Neyman graduated from the Hebrew University of Jerusalem in 1977. His dissertaton, titled "Values of Games with a Continuum of Players", was completed under the supervision of Robert Aumann and was awarded the Aharon Katzir Prize for an Excellent $\mathrm{Ph}$.D. thesis. After graduation he obtained a visiting position at Cornell University, from where he continued on to Berkeley. In 1982 Abraham Neyman joined the Hebrew University of Jerusalem, where he participated in the founding of the Center for the Study of Rationality in 1991. In 1985 he became one of the founders of the Center for Game Theory at Stony Brook University, where he worked for 16 years, in 1989 he was elected as a Fellow of the Econometric Society, and in 1999 he was selected a Charter Member of the Game Theory Society.

Abraham Neyman was the advisor of 12 Ph.D. students. He has thus far published 67 articles and co-edited three books. He has also been the co-organizer of numerous conferences and workshops. He served as the Area Editor for Game Theory in

\footnotetext{
$凶$ Eilon Solan

eilons@post.tau.ac.il

Olivier Gossner

ogossner@gmail.com

Ori Haimanko orih@bgu.ac.il

1 École Polytechnique - CNRS, France, and London School of Economics, Paris, France, UK

2 Department of Economics, Ben-Gurion University of the Negev, Beer-Sheva 84105, Israel

3 School of Mathematical Sciences, Tel Aviv University, Tel Aviv 6997800, Israel
} 
Mathematics of Operations Research between 1987 and 1993, and was a member of the editorial board of both Games and Economic Behavior and the International Journal of Game Theory. At the 2008 World Congress of the Game Theory Society he delivered the inaugural John von Neumann lecture, and in 2014 was elected as the President of the Israeli Chapter of the Game Theory Society.

The first topic to which Abraham Neyman devoted his research was value theory. In Kohlberg and Neyman (1981a), he proved the existence of an asymptotic value for weighted majority games with a non-atomic continuum of players. The proof was facilitated by his fundamental contribution to renewal theory (Neyman 1982). In a subsequent work Abraham Neyman proved that the non-atomicity assumption can be relaxed, while other assumptions are essential (Neyman 1988). He also established diagonality of continuous values, which had implications on further developments of the theory (Neyman 1977). Together with Pradeep Dubey and Robert Weber, Abraham Neyman laid an axiomatic foundation to the theory of semivalues, and demonstrated its importance in political economy (Dubey et al. 1981; Neyman 1984a). Also with Pradeep Dubey, he characterized the well-known equivalence principle that is embodied by the value correspondence, a fundamental notion in economics with origins already in Edgeworth's work (Dubey and Neyman 1984, 1994b). In loose terms, it states that in a large economy consisting of many economically insignificant agents, the core of the economy coincides with the perfectly competitive outcomes, which in the case of differentiable preferences is a unique element, namely the Aumann-Shapley value. His other major contribution was the introduction of the Neyman value, a farreaching generalization of the Aumann-Shapley value to the case of non-differentiable vector measure games (Neyman 2001).

Abraham Neyman's interest in stochastic games was spurred when he attended a workshop at CORE in the winter of 1978-1979, and he commenced his work on the subject with Jean-François Mertens. Together they introduced the concept of the value in stochastic games, and solved one of the main open problems in game theory of the period, namely, the existence of the value in two-player zero-sum stochastic games with finitely many states and actions, (Mertens and Neyman 1981a). He then extended this result for the minmax value and maxmin value in multiplayer stochastic games (Neyman 2003a). Together with Elon Kohlberg he applied operator techniques to study convergence properties of the discounted and finite stage values (Kohlberg and Neyman 1981a). Recently, Abraham Neyman proved the existence of uniform equilibria in multiplayer continuous-time stochastic games, and studied the relation between these equilibria and equilibria of discrete-time approximations of the game (Neyman 2012b, 2013b). Together with Sylvain Sorin, Abraham Neyman studied repeated games with public uncertain duration (Neyman 2003b; Neyman and Sorin 2010; Mertens and Neyman 1981a) and linked equilibria in absorbing games to equilibria in repeated games with symmetric incomplete information Neyman and Sorin (1997, 1998), thereby generalizing previous results regarding zero-sum games.

Abraham Neyman is one of the pioneers in the study of repeated games with boundedly rational players. He modelled boundedly rational players by automata, where the size of the automaton that a player uses measures the complexity of the player. In Neyman $(1985,1999)$ he studied the finitely repeated Prisoner's Dilemma played by finite automata, and showed that the restriction of the players to strategies with bounded 
complexity leads to a folk theorem. He later extended this result to general two-player games, and showed that as the length of the game increases, the limit set of Nash equilibrium payoffs, when the players are constrained to use strategies that are implemented by finite automata, is the set of all feasible and individually rational payoffs, provided the size of the automata that the players can use is subexponential in the length of the game (Neyman 1998). In Neyman and Okada (1999, 2000a) Abraham Neyman and Daijiro Okada presented the notion of strategic entropy and studied the asymptotic behavior of the value of repeated games with finite automata and bounded recall. Together with Olivier Gossner and Penélope Hernández, Abraham Neyman used tools from information theory to characterize the set of equilibrium payoffs in repeated games with asymmetric information on a stream of states of nature in which actions are payoff relevant and serve as a communication device (Gossner et al. 2006).

His work in Game Theory led Abraham Neyman to study various topics in probability theory and functional analysis, such as renewal theory Neyman (1982), vector measures Neyman (1981b), maximal variation of martingales Neyman (2013a), and nonexpansive mappings (Kohlberg and Neyman 1981a, b, 1999).

In retrospect, the work of Abraham Neyman was fundamental to the progress of research in value theory, stochastic games, and repeated games and complexity. A case in point is the ongoing study of the uniform equilibrium and uniform correlated equilibrium in multiplayer stochastic games, which is based on his seminal work with Jean-François Mertens (Mertens and Neyman 1981a).

The majority of articles in the special issue reflect the research interests of Abraham Neyman and have strong links to his works. However, the issue is diverse in scope, as we aimed to accommodate all significant contributions, in particular those of his former students and co-authors.

Olivier Gossner, Ori Haimanko, and Eilon Solan

\section{Appendix}

\section{1 (I) Books}

Hart S, Neyman A (1995) Games and economic theory selected contribution in Honor of Robert J. Aumann. The University of Michigan Press, Ann Arbor

Ichiishi T, Neyman A, Tauman Y (1990) Game theory and applications. Harcourt Brace Jovanovich, Academic Press, San Diego

Neyman A, Sorin S (2003) Stochastic games and applications, NATO Science Series C, vol 570. Kluwer Academic Publishers, Dordrecht

\section{2 (II) Articles}

Aumann R-J, Kurz M, Neyman A (1983) Voting for public goods. Rev Econ Stud L(4):677-693

Aumann R-J, Kurz M, Neyman A (1987) Power and public goods. J Econ Theory, pp 108-127 
Bavly G, Neyman A (2014) Online concealed correlation and bounded rationality. Games Econ Behav 88:71-89

Dubey P, Neyman A, Weber J (1981) Value theory without efficiency. Math Oper Res 6:122-128

Dubey P, Neyman A (1984) Payoffs of non-atomic markets-an axiomatic approach. Econometrica 52:1129-1150

Dubey P, Neyman A (1988) Payoffs in non-atomic games: an axiomatic approach. In: Roth A (ed) The shapley value. Cambridge Univ. Press, Cambridge, pp 207-216

Dubey P, Neyman A (1994a) An axiomatic approach to the equivalence phenomenon. In: Mertens J-F, Sorin S (eds) Game theoretic methods in general equilibrium analysis, NATO ASI Series D. Kluwer Acdemic Publishers, Berlin, pp 137-143

Dubey P, Neyman A (1994b) An equivalence principle for perfectly competitive economies. J Econ Theory 75:314-344

Einy E, Neyman A (1989) Large symmetric games are characterized by completeness of the desirability relation. J Econ Theory 148:369-385

Einy E, Neyman A (1990) On non-atomic weighted majority games. J Math Econ 19:391-403

Forges F, Mertens J-F, Neyman A (1986) A counter example to the folk theorem with discounting. Econ Lett 20:7

Gale D , Neyman A (1982) Nim type games. Int J Game Theory 11:17-20

Gossner O, Hernandez P, Neyman A (2004) Dynamiques de communication. Revue Economique 55:509-516

Hildenbrand W, Neyman A (1982) Integrals of production sets with restricted substitution. J Math Econ 9:71-82

Kohlberg E, Neyman A (1981a) Asymptotic behavior of nonexpansive mappings in normed linear spaces. Israel J Math 38:269-275

Kohlberg E, Neyman A (1981b) Asymptotic behavior of non expansive mappings in uniformly convex Banach spaces. Am Math Mon 88:698-700

Kohlberg E, Neyman A (1983) Convergence in Hilbert's metric and convergence in directions. J Math Anal Appl 93:104-108

Kohlberg E, Neyman A (1999) A strong law of large numbers for nonexpansive vector valued stochastic processes. Israel J Math 111:93-108

Mertens J-F, Neyman A (1981a) Stochastic games. Int J Game Theory, pp 53-66

Mertens J-F, Neyman A (1981b) Minimax theorems for undiscounted stochastic games. In: Mosechlin O, Pallaschke D (eds) Game theory and mathematical economics. North Holland, pp 83-87

Mertens J-F, Neyman A (1982) Stochastic games have a value. Proc National Acad Sci USA 79:2145-2146

Mirman L, Neyman A (1983) Prices for homogeneous cost functions. J Math Econ 12:257-273

Mirman L, Neyman A (1984) Diagonality of cost allocation prices. Math Oper Res 9:66-74

Monderer D, Neyman A (1988) Values of smooth non-atomic games: the method of multilinear approximation. In: Roth A (ed) The shapley value. Cambridge Univ. Press, Cambridge, pp 217-234

Mertens J-F, Neyman A (2003) A value on 'AN'. Int J Game Theory 32:109-120 
Mertens J-F, Neyman A, RosenbergD (2009) Absorbing games with compact action spaces. Math Oper Res 34:257-262

Neyman A (1976) The limiting behavior of the Shapley value in a class of games with many players. Cahiers du Centre d'Etudes de Recherche Operationelle 18:161

Neyman A, Tauman Y (1976) The existence of non-diagonal axiomatic values. Math Oper Res 1:246-250

Neyman A (1977) Continuous values are diagonal. Math Oper Res 2:338-342

Neyman A (1979) Asymptotic values of mixed games. In: Moeschlin O, Pallaschke Diethard (eds) Game Theory and Related Topics. North Holland, pp 71-81

Neyman A, Tauman Y (1979) The partition value. Math Oper Res 2:236-267

Neyman A (1981a) Singular games have asymptotic values. Math Oper Res 6:205212

Neyman A (1981b) Decomposition of ranges of vector measures. Israel J Math 40:54-64

Neyman A (1982) Renewal theory for sampling without replacement. Ann Probab 10:464-481 402

Neyman A (1984a) Semi values of political economic games. Math Oper Res 390-

Neyman A (1984b) Representation of Lp -norms and isometric embedding in Lp -spaces. Israel J Math 48:129-138

Neyman A (1985) Bounded complexity justifies cooperation in the finitely repeated prisoner's dilemma. Econ Lett 19:227-229

Neyman A (1988) Values of vector measure games: are they linear combinations of the measures. J Math Econ 17:31-40

Neyman A (1988) Weighted majority games have an asymptotic value. Math Oper Res 13:556-580

Neyman A (1989) Uniqueness of the shapley value. Games Econ Behav 1:116-118

Neyman A (1991) The positive value of information. Games Econ Behav 3:350-355

Neyman A (1994) Value of games with a continuum of players. In: Mertens J-F, Sorin S (eds) Game theoretic methods in general equilibrium analysis, NATO ASI Series D, vol 77. Kluwer Academic Publishers, Berlin, pp 67-79

Neyman A (1997a) Correlated equilibrium and potential games. Int J Game Theory 26:223-227

Neyman A (1997b) Cooperation, repetition and automata. In: Hart S, Mas Colell A (eds) Cooperation: game-theoretic approaches, NATO ASI Series F. Springer-Verlag, Berlin, pp 233-255

Neyman A (1998) Finitely repeated games with finite automata. Math Oper Res 23:513-552

Neyman A (1999) Cooperation in repeated games when the number of stages is not commonly known. Econometrica 67:45-64

Neyman A (2001) Values of non-atomic vector measure games. Israel J Math 124:127

Neyman A (2002) Values of games with infinitely many players. In: Aumann RJ, Hart S (eds) Handbook of game theory, with economic applications, vol III. Elsevier North Holland, New York 
Neyman A (2003a) Stochastic games and nonexpansive maps in stochastic games and applications. In: Neyman A, Sorin S (eds) NATO ASI series. Kluwer Academic Publishers, Berlin, pp 397-415

Neyman A (2003b) Real algebraic tools in stochastic games in Stochastic Games and Applications. In: Neyman A, Sorin S (eds) NATO ASI series. Kluwer Academic Publishers, Berlin, pp 58-75

Neyman A (2003c) Stochastic games: Existence of the minmax in Stochastic Games and Applications. In: Neyman A, Sorin S (eds) NATO ASI series. Kluwer Academic Publishers, Berlin, pp 173-193

Neyman A (2003d) From markov chains to stochastic games in stochastic games and applications. In: Neyman A, Sorin S (eds) NATO ASI series. Kluwer Academic Publishers, Berlin, pp 9-25

Neyman A, Gossner O, Hernandez P (2006) Optimal use of communication resources. Econometrica 74:1603-1636

Neyman A (2008) Existence of optimal strategies in markov games with incomplete information. Int J Game Theory 37:581-596

Neyman A (2010) Singular games in $b v^{\prime} N A$. J Math Econ 26:384-387

Neyman A, Sorin S (2010) Repeated games with public uncertain process. Int J Game Theory 39:29-52

Neyman A (2012) The value of two-person zero-sum repeated games with incomplete information and uncertain duration. Int J Game Theory 41:195-207

Neyman A (2013a) The maximal variation of martingales of probabilities and repeated games with incomplete information. J Theor Probab 26:557-567

Neyman A (2013b) Stochastic games with short-stage duration. Dyn Games Appl 3:236-278

Neyman A, Okada D (1999) Strategic entropy and complexity in repeated games. Games and economic behavior, special issue in honor of davidblackwell 29:191-223

Neyman A, Okada D (2000a) Repeated games with bounded entropy. Games Econ Behav 30:228-247

Neyman A, Okada D (2000b) Two-person Repeated games with finite automata. Int J Game Theory 29:309-325

Neyman A, Okada D (2009) Growth of strategy sets, entropy, and nonstationary bounded recall. Games Econ Behav 66:404-425

Neyman A, Smordinsky R (2004) Asymptotic values of vector measure games. Math Oper Res 29:739-775

Neyman A, Sorin S (1997) Equilibria in repeated games with incomplete information: the deterministic symmetric case. In: Parthasarathy T et al (eds) Game theoretical applications to economics and operations research. Kluwer Academic Publishers, Berlin, pp 129-131

Neyman A, Sorin S (1998) Equilibria in repeated games with incomplete information: the general symmetric case. Int J Game Theory 27:201-210

Neyman A, Spencer J (2010) Complexity and effective prediction. Games Econ Behav 61:165-168 


\subsection{Other Publications}

Hart S, Neyman A (eds) (1995) Introduction to games and economic theory selected contribution in Honor of Robert J. Aumann. The University of Michigan Press, Ann Arbor, pp 1-28

Neyman A (2006) Aumann Awarded Nobel Prize. Not AMS 53:44-46

\subsection{Unpublished Discussion Papers}

Neyman A (1977) Values for Non-transferable Utility Games with a Continuum of Players. Technical Report No. 351, School of Operations Research and Industrial Engineering, Cornell University

Neyman A, Russo T (2006) Public Goods and Budget Deficit. Discussion Paper Series DP 426, The Federmann Center for the Study of Rationality, the Hebrew University of Jerusalem

Neyman A (2008) Learning Effectiveness and Memory Size. Discussion Paper Series DP 476, The Federmann Center for the Study of Rationality, the Hebrew University of Jerusalem

Levinsky R, Neyman A, Zelený M (2010) Should I Remember more than you? On the best response to factored based strategies. Jena Economic Research Papers 2010-082, Friedrich-Schiller-University Jena, Max-Planck-Institute of Economics

Neyman A (2012b) Continuous-Time Stochastic Games. Discussion Paper Series DP 616, The Federmann Center for the Study of Rationality, the Hebrew University of Jerusalem

Kohlberg E, Neyman A (2015) The cooperative solution of stochastic games. Discussion Paper Series DP 679, The Federmann Center for the Study of Rationality, the Hebrew University of Jerusalem 